Produto \& Produção, vol. 13 n. 2, p. 22-39, jun. 2012

\title{
Produção de gelatina: uma perspectiva competitiva para a cadeia produtiva de frango de corte
}

Recebido em 17/08/2011. Aceito em 21/05/2012.

\section{Poliana Fernandes Almeida}

Mestranda em Engenharia de Produção, Universidade Nove de Julho

Profa, Instituto Federal de Educação de Mato Grosso Campus São Vicente

Departamento de Graduação

poliana.fernandes@hotmail.com

\section{Rosângela Maria Vanalle}

Professora Dra. no Programa de Pós-graduação em Engenharia de Produção

Universidade Nove de Julho

rvanalle@uninove.br

\section{José Carlos Curvelo Santana}

Professor Dr. no Programa de Pós-graduação em Engenharia de Produção

Universidade Nove de Julho

jccurvelo@yahoo.com.br

A cadeia produtiva de frango de corte é pressionada pelos desafios do atual cenário mundial de intensa competitividade e leis de proteção ambiental a fim de buscar fontes alternativas no aproveitamento dos resíduos gerados como os pés de frango, visando vantagem competitiva e uma atividade de maior sustentabilidade. $O$ presente estudo propõe a produção de gelatina como uma nova perspectiva para a cadeia produtiva de frango discutindo os principais elos envolvidos, contribuindo dessa forma com a comunidade acadêmica e científica com informações sobre aproveitamento de subprodutos na busca pela sustentabilidade e competitividade. Nesse sentido, apresenta-se um processo experimental de elaboração de gelatina a partir de tarsos de frango. A análise de aceitabilidade foi realizada por meio de análise sensorial. A proposta de novo destino aos pés de frango, considerados resíduos nos frigoríficos, foi possível, obtendo-se, portanto, vantagem competitiva tanto para o frigorífico, propiciando fonte alternativa de lucro, como para a indústria de gelatina onde a inovação em tipo de matéria-prima e novos processos industriais determinam adaptabilidade, flexibilidade no processamento e competitividade no mercado.

Palavras-chave: cadeia produtiva; vantagem competitiva; gelatina. 
The broiler production chain is pressed by the challenges of the current global scenario of intense competitiveness and environmental protection laws to seek alternative sources in the recovery of waste generated as the chicken feet seeking competitive advantage and a more sustainable activity. This study proposes the production of gelatin as a new perspective to the broiler production chain discussing the main links involved, thus contributing with the academic and scientific community with information on utilization of byproducts in the quest for sustainability and competitiveness. In this sense, it presents an experimental process of producing gelatin from chicken feet. The analysis of acceptability was conducted by means of sensory analysis. The proposed of new destination for chicken feet, considered as waste in the slaughterhouses, was possible, obtaining, therefore, a competitive advantage for both the slaughterhouses, providing an alternative source of income, as for gelatin industry where innovation in type of raw material and new industrial processes determine adaptability, flexibility in processing and market competitiveness.

Keywords: Production chain; competitive advantage; gelatin.

\section{INTRODUÇÃO}

A economia de vários países tem sido movimentada pelo comércio da carne de frango e apesar da crise internacional, o mundo produziu mais frango em 2009. Segundo os levantamentos divulgados, a avicultura mundial produziu no ano de 2009 cerca de 71,715 milhões de toneladas, 280 mil toneladas a mais que em 2008. O Brasil encerrou o ano de 2009 como terceiro maior produtor, encontrando-se na mesma colocação de 2008. O país produziu 10,9 milhões de toneladas em 2009, o que representou $15,3 \%$ da produção mundial (UBA, 2009). A Ubabef divulgou que a produção de carne de frango chegou a 12,230 milhões de toneladas em 2010, em um crescimento de 11,38\% em relação a 2009 (UBABEF, 2010).

Com este desempenho, o Brasil se aproxima da China, hoje o segundo maior produtor mundial, cuja produção de 2010 teria somado 12,550 milhões de toneladas, abaixo apenas dos Estados Unidos, com 16,648 milhões de toneladas, conforme projeções do Departamento de Agricultura dos EUA (USDA, 2010).

Com relação à exportação, o Brasil é o maior exportador mundial de carne de frango, e de acordo com informações da ABEF (2010) as exportações somaram 3,63 milhões de toneladas em 2009 e 3,819 milhões de toneladas em 2010 representando, portanto, um aumento de $5,1 \%$, um novo recorde histórico para a carne de frango, principal produto das exportações avícolas brasileiras.

A carne de frango no decorrer dos anos deixou de ser uma carne nobre destinada exclusivamente às classes superiores. Hoje, este alimento está difundido por todas as classes sendo inclusive fruto de marketing político. Além da melhoria significativa do consumo interno, a produção nacional atende ao mundo com grande dinamismo e qualidade (VIEIRA JÚNIOR et al, 2006). Esse aumento no consumo de carne de frango nas últimas décadas pode ser atribuído à queda do preço do produto pelos ganhos tecnológicos e ainda ao resultado da produção em 2010 . O consumo "per capita" aumentou significativamente nos últimos anos, e 29,9 kg em 2000, 38,1 kg em 2009 a 44 kg em 2010 (ABEF, 2010). 
A avicultura brasileira oferece aos consumidores uma grande diversidade de produtos que atendem às necessidades de praticidade e conveniência, visto que o consumo de cortes e produtos elaborados vêm crescendo em detrimento do consumo do frango inteiro (MARTINS et al, 2006). Isto é confirmado pela União Brasileira de Avicultura (2009) que destaca o futuro crescimento da produção com maior valor agregado, com a disseminação dos alimentos "semiprontos". A elasticidade da renda do brasileiro, o aumento da classe trabalhadora e o novo perfil da família brasileira com menos tempo para dedicar ao preparo de alimentos serão fundamentais nesse mercado.

O sistema agroindustrial brasileiro está exposto a um ambiente bastante competitivo pela globalização econômica, ao livre comércio e avanço tecnológico, o que geram ao mesmo tempo, oportunidades de investimento percebidas pelo setor privado e necessidade de novas relações, posturas e formas de conduta para os agentes da agroindústria (JANK, 1996). A cadeia produtiva da avicultura de corte é, provavelmente, uma das cadeias produtivas brasileiras com maior nível de coordenação, conferindo-lhe grande competitividade no mercado mundial (ARAÚJO et al, 2008).

A competição tem influenciado as indústrias a desenvolverem novas fontes de vantagens competitivas, exigindo um processo contínuo de inovação. Isso tem induzido as empresas a gerarem e utilizarem tecnologias ou ferramentas que venham a criar oportunidades para novos produtos, serviços e processos industriais (SIMON; SATOLO, 2009). Pressionada pelos novos desafios, a avicultura procura se enquadrar de acordo com o novo cenário mundial de intensa competitividade e leis de proteção ambiental. Os resíduos originados passam a ser parte integrante do processo produtivo, ressaltando a importância da escolha do melhor destino destes, visando uma atividade de maior sustentabilidade.

Para Padilha et al, (2005), as questões relacionadas ao meio ambiente, como o aproveitamento dos resíduos, consolidam-se como uma preocupação crescente das empresas, entendendo que as pressões de ordem legal tornam-se cada vez mais evidentes e complexas para a gestão das organizações, o que vem ao encontro da necessidade de determinação de padrões de desempenho que estejam alinhados à estratégia, objetivos e metas da organização, tornando indissociáveis os fatores competitivos organizacionais das ações de proteção ambiental.

Nesse sentido, objetivou-se com o presente estudo analisar a inserção da produção de gelatina a partir de colágeno extraído de tarsos de frango na cadeia produtiva de frango de corte como alternativa competitiva, contribuindo dessa forma como material que possibilite à comunidade acadêmica e ao mundo científico informações adicionais sobre aproveitamento de subprodutos na busca pela sustentabilidade e competitividade.

\section{METODOLOGIA}

Levando-se em consideração que o desenvolvimento de novos produtos, a partir de subprodutos e/ou resíduos, trata-se não somente de uma consciência ambiental como também de estratégia competitiva e ainda, tendo em vista que os tarsos de frango possuem propriedades químicas interessantes à produção de gelatina comestível, realizou-se um estudo sobre os principais destinos desta matéria-prima de forma a incluir a indústria de gelatina como parte da cadeia 
produtiva de frango de corte. Para tanto, uma pesquisa bibliográfica foi realizada, baseando-se em consulta a artigos científicos selecionados, por meio de um sistema de busca em banco de dados do SciELO (Scientific Eletronic Library Online) e Scopus-Elsevier, além de anais de congressos e bibliotecas de universidades renomadas. O foco da pesquisa foi a interação entre os conceitos de competitividade, sustentabilidade, cadeia produtiva de frango de corte e o aproveitamento de subprodutos.

Dentro desse contexto, dividiu-se este trabalho em três momentos. No primeiro momento discute-se a relação entre competitividade, sustentabilidade, cadeia produtiva de frango de corte e seus principais elementos, levando-se em consideração o processamento da carne de acordo com as informações encontradas. No segundo momento apresenta-se uma pesquisa experimental sobre o aproveitamento de tarsos de frango na extração de colágeno e produção de gelatina tipo sobremesa, discutindo-se a sua viabilidade e principais vantagens competitivas dessa fonte alternativa. Em tal estudo propõe-se uma metodologia inovadora para a extração de colágeno de tarsos de frango e o processamento deste em gelatina comestível (tipo sobremesa). Por fim, no terceiro momento, com a finalidade de se verificar a aceitabilidade do produto, realizou-se análise sensorial do produto final.

\subsection{Competitividade e sustentabilidade}

A busca por ganho de competitividade e redução de desperdícios tem se tornado uma constante para as empresas (MELO; ALCÂNTARA, 2009). A competitividade global acompanha o dia-a-dia das organizações, impactando não somente os parâmetros de mercado (prazo de entrega, preço final e qualidade do produto/serviço), mas também as características intrínsecas às empresas na gestão dos seus processos (SEBRAE, 2009).

De acordo com Porter (1993), competitividade é a habilidade ou talento

resultante de conhecimentos adquiridos capazes de criar e sustentar um desempenho superior ao desenvolvido pela concorrência. Benites \& Valério (2004) analisando o modelo de concorrência e competitividade de Schumpeter, indicam que a concorrência caracteriza-se pela busca da diferenciação, via estratégias competitivas, como fator chave para obtenção de vantagem competitiva, e desta forma, atingir um desempenho superior. Assim, a concorrência é vista como um processo ativo de criação de espaços e oportunidades por meio de inovações, num sentido amplo,

não se restringindo apenas em mudanças tecnológicas, mas considerando a inovação como qualquer esforço que vise o desenvolvimento de novos processos produtivos, fontes de matéria-prima, dimensões gerenciais ou campo de atuação da empresa.

Nos estudos de Linton et al (2007) sobre cadeia de suprimentos sustentáveis considerou-se não somente o produto a partir de uma primeira transformação da matéria-prima até a entrega ao cliente, mas também integrando a sustentabilidade às questões e os fluxos que se estendem para além do núcleo de gestão da cadeia de suprimentos como design de produto, produção de subprodutos, subprodutos produzidos durante o uso do produto, extensão de vida de produto, produto em final de vida e os processos de recuperação em final de vida. 
A análise do ciclo de vida, segundo Dias (2009), é um instrumento de estudo dos aspectos e impactos ambientais associados a um produto, processo ou serviço. Tal avaliação, além da preocupação ambiental, objetiva melhorar a competitividade de produtos em mercados com preocupações conceituais de sustentabilidade, além de reduzir custos de produção, ao incluir decisões de final de vida para os produtos. Cada vez mais valorizada pelo consumidor, a consciência ambiental tem se tornado um diferencial, não somente pela imagem da empresa que o adota, mas pelo impacto real que ocorre no meio ambiente.

Considerando o aproveitamento de subprodutos, acredita-se nesta pesquisa que a cadeia de suprimentos deve ser ampliada para incluir explicitamente os subprodutos dessa cadeia, a considerar o ciclo de vida completo do produto. $O$ aproveitamento de tarsos de frango para extração de colágeno com posterior produção de gelatina, visa contribuir com a sustentabilidade minimizando os resíduos da indústria avícola e proporcionando um destino mais nobre deste por meio do desenvolvimento de um novo produto agregando valor dessa forma à cadeia produtiva de frango de corte.

\subsection{Cadeia produtiva de frango de corte}

A cadeia produtiva é o conjunto de elos, compreendendo os sistemas produtivos agropecuários e agroflorestais, fornecedores de serviços e insumos, indústrias de processamento e transformação, distribuição e comercialização, além de consumidores finais do produto e subprodutos da cadeia. As cadeias agrícolas objetivam suprir o consumidor final de produtos em qualidade e quantidade compatíveis com as suas necessidades e a preços competitivos (CASTRO et al, 1995).

Nas últimas três décadas, a avicultura brasileira alcançou níveis de produtividade comparáveis aos obtidos nos principais países concorrentes. Isto é resultado da coordenação de toda a cadeia e do uso de uma estratégia de produção baseada na parceria entre produtor e indústria (MARTINS et al, 2006).

$\mathrm{Na}$ cadeia produtiva de frango de corte há duas formas de integração, por meio de contratos, onde o produtor recebe o pinto de um dia, responsabilizando-se pelo manejo de engorda e, quando o frango atinge a fase adulta, entrega-o para a empresa integradora (frigorífico), que abate, processa e comercializa o produto e por integração que feita pela verticalização da empresa. Nas duas formas de integração, porém, há o controle total por parte da empresa integradora (o frigorífico). Geralmente, ela atua desde a produção da ração, dos pintos, até no abate, no processamento e na comercialização (ARAÚJO et al, 2008).

De acordo com Vieria Júnior et al, (2006), a vantagem maior da contratação na produção de frango, da ótica dos integradores, é adquirir o controle da produção sem incorrer nos investimentos necessários na opção da produção própria via integração de fato. Uma vantagem adicional da produção sob contrato é dispensar a contratação de muitos funcionários, o que tornaria complexa e onerosa a administração do conjunto.

A garantia da sustentabilidade da cadeia passa pela distribuição dos ganhos por ela obtidos ao longo de toda a sua extensão (ARAÚJO et al, 2008). No caso da cadeia produtiva do frango de corte, há três elos concentrados e com poder relativamente grande de fixação de preços: os avozeiros, os frigoríficos e os 
supermercados. O segmento constituído pelos abatedouros/frigoríficos/indústrias de transformação do frango atua na cadeia que articula o desempenho de uma multiplicidade de agentes, e cabe a ele grande parte da coordenação do funcionamento da cadeia produtiva do frango de corte. Já os supermercados, gerenciados por grandes corporações multinacionais, possuem uma coordenação e poder de venda que acaba por torná-las as grandes marcadoras de preços na cadeia produtiva do frango de corte (FREITAS, 2008).

Vieira Júnior et al, (2006) destacam os agentes que compõem a cadeia biológica: as granjas avozeiras, de matrizes, o incubatório e a granja de engorda. A escolha da linhagem genética das galinhas matrizes, que é transmitida hereditariamente aos ovos fertilizados, e destes aos pintos, proporcionará aos futuros frangos de corte um padrão estabelecido de produção em termos qualitativos e quantitativos. As granjas avozeiras que estão sediadas no Brasil obtêm seu plantel pela importação das denominadas galinhas avós. Pelos cruzamentos entre as avós importadas, via licença de tecnologia, obtêm-se as linhagens direcionadas para a produção de frango de corte. De acordo com Araújo et al (2008), o avozeiro é o primeiro elo da cadeia produtiva, onde ficam as galinhas avós, que são originadas a partir da importação de ovos das linhagens avós, as quais são cruzadas para produzir as matrizes que, por sua vez, vão gerar os pintos comerciais criados para o abate. Isso pode ser verificado na Figura 1.

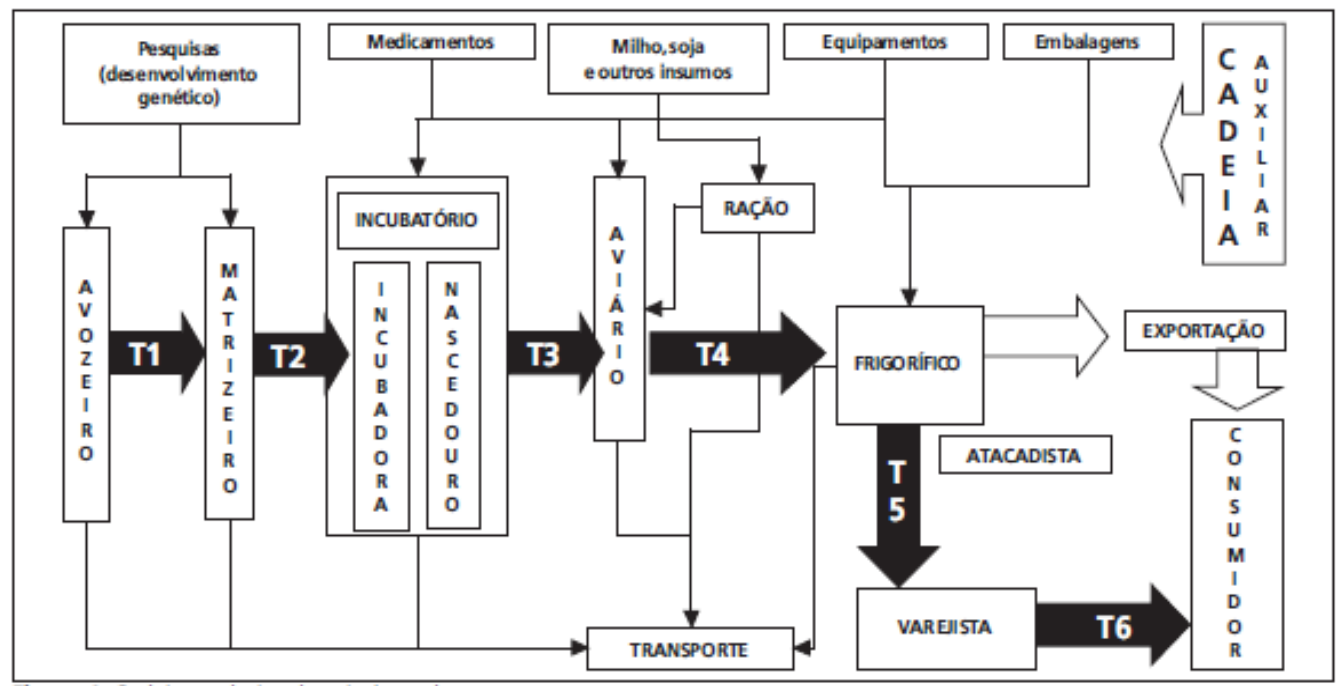

Figura 1 - Cadeia produtiva da avicultura de corte. Fonte: Paiva et al (2005)

Na granja de matrizes é o local onde são produzidos os ovos férteis. Dentre as linhagens disponíveis pelos avozeiros, o matrizeiro entra em contato com a esfera superior da cadeia e adquire as aves que são criadas por um período de seis meses até que se inicie o processo de produção de ovos, o qual perdura por 45 semanas (VIEIRA JÚNIOR et al, 2006).

O incubatório/nascedouro é o terceiro elo da cadeia produtiva, unidades pertencentes geralmente ao frigorífico, que recebem os ovos para "chocá-los" e, na sequência do processo, passam-nos para os nascedouros, cujo objetivo é dar origem aos pintos de corte que serão encaminhados para os aviários após algumas horas de seu nascimento. O aviário é o quarto elo da cadeia produtiva e corresponde a uma etapa de produção, caracterizada pelos contratos de integração 
entre frigoríficos e produtores rurais (integrados). É no aviário que se dá o crescimento e a engorda dos pintos, que ali chegam com algumas horas depois de nascidos e ficam até a época de abate, aos 43 dias, aproximadamente. O frigorífico, quinto elo da cadeia produtiva é onde se origina o produto final - o frango resfriado, congelado, inteiro e em cortes/pedaços. A partir desta etapa, surge a figura do "varejista" como sexto elo, incluindo-se aqui as empresas de exportação. A figura do atacadista não aparece como um elo individual porque o próprio frigorífico desempenha este papel. Na sequência, está o último elo, o do "consumidor final" (ARAÚJO et al, 2008).

É justamente no quinto elo da cadeia produtiva de frango de corte, que se encontra uma das maiores produções de subprodutos. Nesse sentido, o foco desta pesquisa, tendo como objeto de estudo a competitividade gerada pelo aproveitamento dos tarsos de frango na produção de gelatina, está no frigorífico.

\subsection{Processamento da carne de frango}

As empresas processadoras de carne de frango, acompanhando as necessidades dos consumidores, passaram a oferecer o frango industrializado, que antes era encontrado no mercado apenas como o tradicional frango inteiro. A mudança nos hábitos do consumidor influenciou na oferta de produtos em maior número e mais elaborados. Para se obter produtos mais elaborados, é preciso que a indústria, no seu sistema produtivo, garanta altos padrões de qualidade em todas as etapas do processo produtivo, ou seja, desde o fornecimento dos insumos de produção agrícola e industriais até a venda no varejo (PEREIRA et al, 2007).

O aproveitamento dos resíduos e subprodutos agropecuários torna-se a cada dia uma preocupação constante, tanto dos órgãos governamentais como das empresas particulares. O setor avícola empresarial brasileiro deu importância à sustentabilidade e à necessidade de produzir adequando-se à preservação ambiental no momento em que se criaram normas internacionais para a mensuração da qualidade ambiental, aliada à grande concorrência internacional exigindo a adequação ambiental das empresas exportadoras. Ocorreram ainda modificações na legislação ambiental, tornando-se mais restritiva e intensificando a fiscalização (PALHARES, 2005).

É preciso que as empresas trabalhem sua estratégia de marketing, identificando nichos de mercado, diferenciando produtos para satisfazer esses nichos, valorizando a qualidade nutricional de seu produto final, a qualidade dos insumos e a conservação do meio ambiente. De acordo com Roque (1996), nas operações de corte e desossa das aves sobram como subprodutos, grandes quantidades de partes menos nobres, cujos valores alimentar e comercial são menores. Estas, por sua vez, para não entrarem em processo de decomposição, precisam ter um destino adequado que não polua o meio ambiente e que esteja de acordo com a legislação que regula o destino final dos resíduos (PADILHA, 2006).

Isso é verificado por Pardi (1995), ao expor que nas indústrias de produtos cárneos, os resíduos são frequentemente muito volumosos e representam um problema sério, pelo alto teor de matéria orgânica nele contido, e estes resíduos podem se comportar como focos de proliferação de microrganismos. Assim, o trato inadequado dos resíduos industriais também contribui para o agravamento dos problemas ambientais, pois, os produtos que não podem ser transformados em 
farinhas, são lançados nos rios, levando, à poluição, com consequências já conhecidas.

Apesar dos fins comerciais dos resíduos gerados no abate de frangos, as pesquisas nessa área não têm avançado muito no sentido de identificar outras formas e/ou tecnologias de tratamento e destinação, sendo estas uma preocupação da indústria avícola do Brasil. Algumas empresas vêm desenvolvendo gradualmente tecnologias voltadas para a busca de alternativas que resolvam esses gargalos identificados no âmbito ambiental que se relaciona à produção (PADILHA, 2006).

O processamento das aves ocorre basicamente para que ocorra a conversão da carne em um produto comestível, eliminando componentes não- desejados, tais como: sangue, penas, vísceras, patas, cabeça e ainda evitar contaminação bacteriana. A qualidade final do produto depende não somente da condição em que estava a ave ao chegar ao local para ser processada, mas também como a ave é manipulada durante a operação (SARCINELLI et al, 2007).

Sendo assim, diante do cenário atual, onde a competitividade impera entre as empresas, especial atenção vem sendo dada para minimização ou reaproveitamento de resíduos sólidos gerados nos diferentes processos industriais. Dentro desse contexto, o resíduo representa um problema econômico para a empresa (desperdícios de carnes boas, gastos com eliminação de resíduos e tratamento destes até um nível ambientalmente aceitável) e um problema ambiental para a sociedade (ROQUE, 1996). Resíduos produzidos na produção que por várias razões não têm aplicação, constituem preocupação em suas fontes, por suscitarem sua presença problemas de poluição e de contaminação (EVANGELISTA, 1989).

O frigorífico (unidade industrial ou abatedouro) é o quinto elo da cadeia produtiva, onde se origina o produto final - o frango resfriado, congelado, inteiro e em cortes/pedaços. É composto na sua maioria por várias seções no processo produtivo (BUENO et al, 2006). Dentro desse contexto há vários subprodutos que são considerados como resíduos e que na maioria das vezes são usados para a fabricação de farinha. Mas, partes destes resíduos podem ser aproveitados para o desenvolvimento de um produto novo para alimentação humana ou como ingrediente alternativo para produtos já existentes.

Em uma pesquisa sobre a gestão ambiental de resíduos da produção na Perdigão Agroindustrial S/A - Unidade Industrial de Serafina Corrêa - RS, Padilha et al, (2005) verificaram que eram produzidos cerca de $1.500 \mathrm{~kg}$ diariamente. De acordo com Roque (2004), os pés e ossos com resíduos de carne aderida possuem em sua composição cerca de $15 \%$ de água, $14 \%$ de gordura, $32 \%$ de osseína (matéria orgânica), $38 \%$ de substâncias minerais como essencialmente fosfato de cálcio $(85 \%)$, carbonato de cálcio $(10 \%)$ e fosfato de magnésio $(1,5 \%)$. Os pés de frango também possuem grandes quantidades de colágeno, proteína coloidal solúvel em água, obtida por hidrólise controlada. Os tarsos de frango, conjuntamente com os ossos limpos, podem ser utilizados para a fabricação de gelatina.

Tendo em vista que os tarsos de frango possuem propriedades químicas interessantes à produção de gelatina comestível, torna-se necessário verificar mediante este trabalho as vantagens competitivas dessa matéria-prima alternativa juntamente com a aceitabilidade desse produto a partir da avaliação de suas qualidades sensoriais. 


\subsection{Aproveitamento de tarsos de frango e vantagem competitiva: estendendo a cadeia produtiva de frango de corte}

A grande maioria das gelatinas comerciais é derivada de mamíferos, principalmente obtidas a partir de pele de suíno e couro bovino, mas por muitas razões socioculturais cresce a exigência de fontes alternativas. Algumas destas razões são, por exemplo, restrições religiosas como a do judaísmo e islamismo, e doenças relacionadas a bovinos (YAN et al, 2007; GIMÉNEZ et al, 2009) especialmente desde o surto de BSE (doença da vaca louca) (GUDMUNDSSON, 2002; CHO et al, 2005).

A procura por novos agentes de geleificação para substituir a gelatina de mamíferos tem norteado várias pesquisas sobre diferentes matérias-primas, como por exemplo, a gelatina de origem marinha (pele de peixe, ossos e barbatanas) (HAUG et al, 2004), e outros trabalhos que têm como foco a extração e classificação da gelatina a partir de pescados (BADII; HOWELL, 2006; HAUG et al, 2004; ANERSEN; GILDBERG, 2007), porém trata-se de fonte pouco utilizada.

A busca por fontes alternativas na obtenção de gelatina trata-se também de uma questão ambiental, sendo ressaltada por Serra \& Oliveira (2006) que revelam que na obtenção da raspa de couro bovino, material menos nobre do que o couro, utilizada na produção de gelatina, durante seu processamento gera resíduo que contém cromo, produto geralmente descartado, que por sua vez pode vir a contaminar o meio ambiente.

Outros fatores que devem ser considerados no que se refere à pele suína, é que apenas $0,2 \%$ do total de animais abatidos têm a pele destinada para o curtimento, pois não existe um cuidado diferenciado nas granjas de suínos para a extração da pele no animal. Os cuidados da suinocultura moderna visam o suíno como um todo. Além disso, existe uma limitação de $10 \%$ de teor de gordura presente no couro do animal para sua utilização na industrialização de gelatina alimentícia. Dessa forma, o preço do quilo da pele suína para fabricação de gelatina alimentícia gira em torno de R\$ 0,95 (QUEVEDO, 2005). Segundo Serra \& Oliveira (2006), o valor da matéria-prima provinda de bovinos, cujo peso de cada pele gira em torno de $40 \mathrm{~kg}$ é vendida ao preço de $\mathrm{R} \$ 1,50 \mathrm{o} \mathrm{kg}$. Sendo, portanto, uma fonte de colágeno de maior custo comparada à de frango o que indica vantagem competitiva dos tarsos de frango.

Essa vantagem competitiva pode ser verificada nos estudos de Alves \& Prudêncio-Ferreira (2002) que extraíram colágenos de peles e pés de frangos. O rendimento dos materiais colagenosos desidratados foi cerca de $16 \%$ em relação ao peso de peles e tendões "in natura", enquanto que Quevedo (2005) expõe que de uma carcaça suína normal podem ser retirados, em média, $5,5 \mathrm{~kg}$ de pele e desta é obtida uma solução de apenas aproximadamente $5 \%$ de gelatina no processo de extração. Lopes (1976) estudou a utilização de tarsos de aves para elaboração de gelatina comestível, porém não há trabalhos sobre a transformação do produto final incluindo análises sensoriais de gelatinas produzidas com colágeno extraído de tarsos de frango e vantagem competitiva. 


\subsection{Extração do colágeno e produção de gelatina tipo sobremesa}

As etapas de obtenção de gelatina provinda de matérias-primas tradicionais (pele suína e raspa de couro bovino) utilizadas pelo Grupo Gelita são iniciadas por um pré-tratamento da matéria-prima onde estão envolvidos dois processos principais a serem empregados na fabricação de gelatina, o processo ácido onde a matériaprima (principalmente a pele suína) é submetida a um processo de pré-tratamento de três dias. Este tratamento é realizado com ácido e prepara a matéria-prima para o processo subsequente de extração. E o processo alcalino que perdura por um período de várias semanas transforma-se lentamente a estrutura do colágeno. Este processo somente pode ser aplicado quando a matéria-prima for osseína ou raspa bovina (GELITA, 2010).

A técnica adotada por Lopes (1976), utilizando tarsos de aves, consistiu em colocar os pés das aves, já lavados e picados, de molho em solução de ácido clorídrico a $0,3 \%$, em temperatura ambiente durante $20 \mathrm{~h}$ com posterior eliminação do excesso de ácido por meio de lavagem com água corrente. Após foram adicionadas duas partes de água e o pH ajustado em torno de 6,0. O material era então aquecido por tempos e temperaturas variáveis.

$\mathrm{Na}$ etapa de extração adotada pelo grupo Gelita, o material pré-tratado recebe água quente e passa por um processo de extração de múltiplos estágios obtendo-se uma solução de aproximadamente $5 \%$ de gelatina, isso ressalta-se de matéria-prima tradicional, em que posteriormente passa pelas etapas de purificação, concentração, secagem, moagem e mistura (GELITA, 2010).

Nesta pesquisa, propõe-se a utilização de matéria-prima inovadora e uma metodologia diferenciada para extração de gelatina, onde não há a utilização de ácidos e álcalis focando-se a extração principalmente na operação unitária de cocção. Este processo visa também à preservação das propriedades nutricionais dos tarsos de frango já que as macerações e os processos de extração empregados tradicionalmente eliminam a maioria das frações proteicas importantes nutricionalmente.

Na produção de gelatina proposta pelo presente estudo, primeiramente cerca de $500 \mathrm{~g}$ de tarsos de frango foram submetidos à operação de toalete como retirada das unhas e lavagem a fim de remover possíveis resíduos de sujidades. Posteriormente, os mesmos foram submetidos ao processo de cocção a uma temperatura de $120^{\circ} \mathrm{C}$ por 20 min conforme é mostrado na Figura 2. 


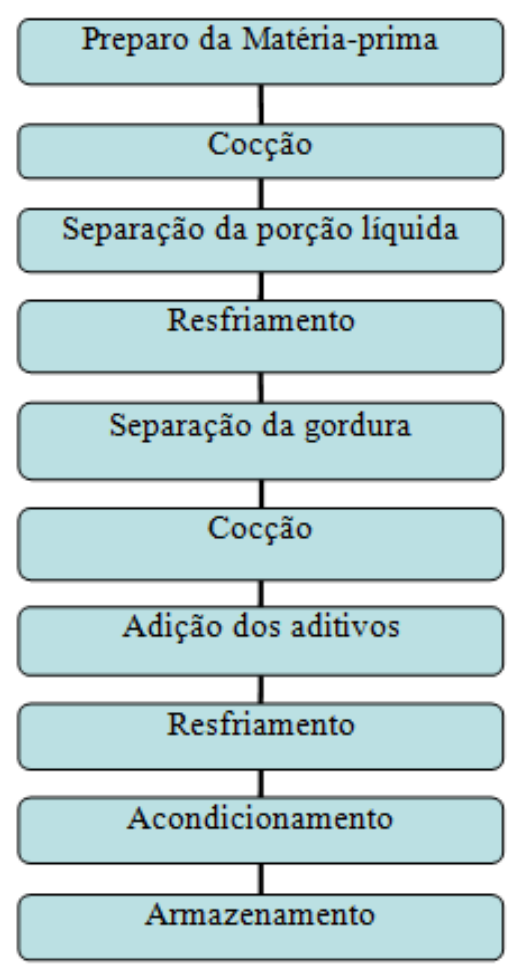

Figura 2 - Fluxograma de produção de gelatina a partir de pés de frango. Fonte: Elaborado pelos autores

Após a cocção, a porção líquida resultante foi separada, purificada e a amostra foi colocada em recipiente de vidro sendo submetida ao resfriamento. Após o resfriamento, a gordura acumulou-se na superfície, pela densidade inferior, facilitando sua separação com auxílio de uma colher e posterior descarte. Como se trata de um projeto piloto optou-se aleatoriamente pelas seguintes quantidades em sua formulação: colocaram-se $500 \mathrm{~mL}$ da porção líquida resultante do processo de extração (mistura de colágeno e água) em um recipiente de inox e aquecida juntamente com $200 \mathrm{~g}$ de açúcar refinado e os aditivos como 0,5 g de conservante sorbato de potássio e $10 \mathrm{~g}$ de SIBER® (sabor uva), cuja composição incluía corantes artificiais bourdeaux $\mathrm{S}$ e azul brilhante FCF, amido, ácido cítrico, regulador de acidez e antiumectante. A gelatina foi denominada GU (gelatina sabor uva).

\subsection{Análise Sensorial}

A avaliação sensorial da gelatina produzida a partir de tarsos de frango sabor uva (GU) foi realizada por 30 provadores não- treinados abrangendo indivíduos de ambos os sexos, com idade entre 15 e 25 anos, no Laboratório de Análise Sensorial de Alimentos (LASA) do IFMT Campus São Vicente localizado em Cuiabá, Mato Grosso. As amostras foram servidas em copos plásticos descartáveis codificados com quantidades padronizadas juntamente com a ficha de avaliação.

Utilizou-se a escala hedônica de 9 pontos, em que os provadores avaliaram o quanto gostaram ou desgostaram da amostra, sendo que os pontos correspondiam a: 1 - desgostei muitíssimo, 2 - não gostei muito, 3 - não gostei regularmente, 4 não gostei ligeiramente, 5 - indiferente, 6 - gostei ligeiramente, 7 - gostei 
regularmente, 8 - gostei muito e 9 - gostei muitíssimo, assim como o teste de disponibilidade em se consumir a gelatina com escala de 1 - não consumiria até 6 consumiria todos os dias (STONE; SIDEL, 1993; FAKHOURI et al, 2007). Os testes afetivos são utilizados quando se necessita conhecer o "status afetivo" dos consumidores com relação ao produto, e para isso são utilizadas as escalas hedônicas. Dos valores relativos de aceitabilidade pode-se inferir a preferência (FERREIRA, 2000).

A escala hedônica utilizada nesta pesquisa é a mais empregada para avaliar a aceitação de alimentos, pois tem como principal vantagem a sua facilidade de entendimento e uso por provadores não- treinados, o que as tornam as opções preferenciais em testes com consumidores. O grande uso desta escala se deve, notadamente, à sua confiabilidade e suficiente sensibilidade para detectar diferenças de aceitação entre amostras (CARDELLO; SCHUTZ, 1996). Os resultados obtidos com a aplicação dos questionários foram tabulados, tendo em vista a frequência das respostas (TEIXEIRA et al, 1987).

\section{RESULTADO E DISCUSSÕES}

O estudo sobre a importância da utilização de subprodutos, neste caso dos tarsos de frango na produção de gelatina indica uma alternativa competitiva; na Figura 3 são destacados os destinos dos pés de frango e a inserção da indústria de gelatina no processamento da carne de frango em frigorífico. De acordo com Rousselot (2010), os tipos de gelatinas produzidas pelas indústrias podem ter diversas aplicações: técnicas (fósforo, cosméticos etc), farmacêuticas (cápsulas, comprimidos), tecnologia de imagem (fotografia) e ainda alimentícias (confeitos, sobremesas, produtos cárneos etc). Nesta pesquisa enfatiza-se a aplicação alimentícia, mais especificamente sobremesa: gelatina.

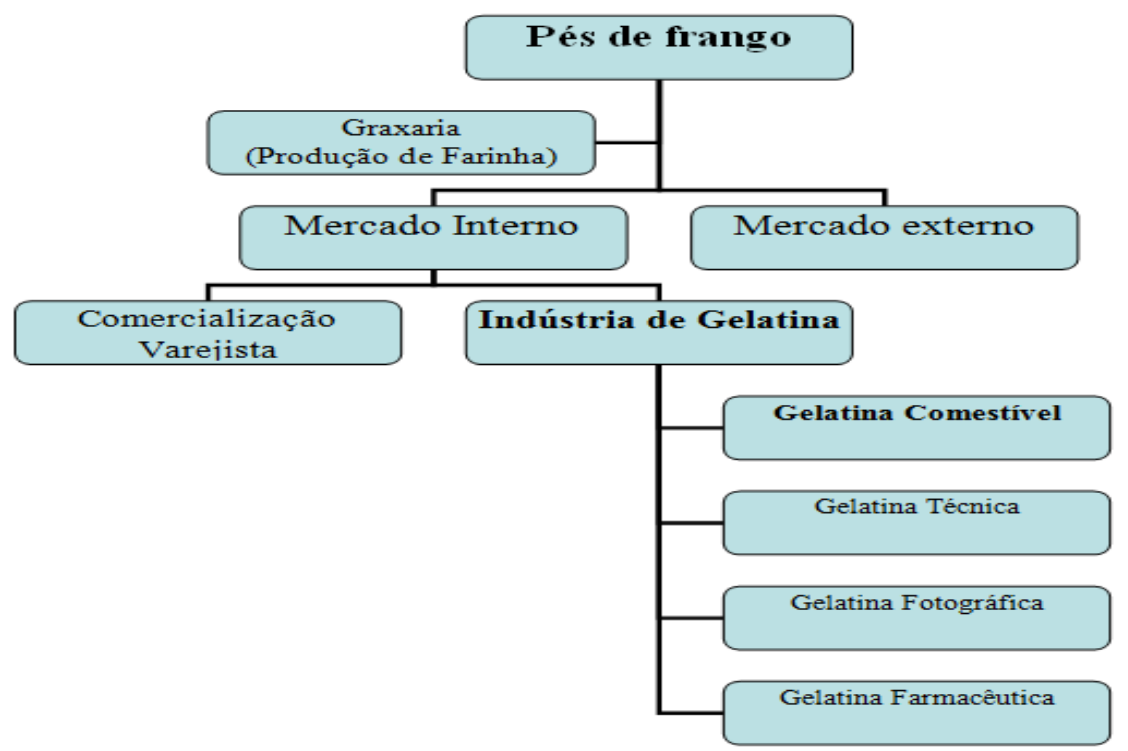

Figura 3 - A Indústria de gelatina como destino alternativo aos pés de frango. Fonte: Elaborado pelos autores. 
$\mathrm{Na}$ Tabela 1 é apresentado o rendimento em material extraído dos tarsos (pés) de frango. Como se vê o material que pode ser usado na produção de gelatina é cerca de $36 \%$ do peso total de pés de frango utilizado. Assim de 1 ton de pés de frango adquirida pode-se obter até $355,4 \mathrm{~kg}$ de gelatina, o que é um rendimento bastante significativo, principalmente se considerarmos que essa 1 ton da matériaprima é adquirida por apenas R\$1,00 (MFRURAL, 2010). Dentro desse contexto pode-se verificar mais vantagens competitivas da gelatina provinda de tarsos de frango, como sendo rendimento e valor da matéria-prima.

Tabela 1 - Composição química dos tarsos de frango.

Constituintes Valor médio $(\mathrm{g} / 100 \mathrm{~g})$

Umidade (\%) $\quad 64,46$

Gelatina (\%) $\quad 35,54$

Fonte: Alves \& Prudêncio-Ferreira (2002).

Na Tabela 2 são mostrados os valores médios da análise sensorial da gelatina de pés de frango. Analisando-se as médias obtidas, verificam-se valores próximos a 7 , indicando que a maioria dos provadores, responderam que "gostaram" desta gelatina.

Tabela 2 - Avaliação das qualidades sensoriais das gelatinas de pés de frango sabor uva.

Valores Sensoriais Médios

\begin{tabular}{l|l|l|l|l}
\hline Amostras & Aroma & Cor & Sabor & Textura \\
\hline Gelatina Uva Experimental (GU) & 7,7 & 7,5 & 7,0 & 6,4 \\
\hline
\end{tabular}

Fonte: Elaborado pelos autores

Supõe-se que a média do atributo "textura" deve-se ao fato de que a gelatina experimental de uva apresentou-se mais consistente que os produtos disponíveis no mercado, causando certa estranheza aos consumidores habituados a produtos de consistência menor. O que pode ser comprovado pela quantidade de água presente nas amostras, já que uma quantidade maior de água na composição torna o produto menos consistente do que outro.

Com relação à disponibilidade em se consumir as amostras de gelatinas, verificou-se que os valores atribuídos pelos provadores para as intenções de "consumiria de vez em quando" a gelatina experimental (GU) foram cerca de $26,6 \%$, sendo que mais de $83 \%$ dos avaliadores responderam que têm intenções de consumir a gelatina obtida de tarsos de frango, indicando boa aceitabilidade.

Segundo Alves \& Prudêncio-Ferreira (2002), a matéria-prima utilizada para a obtenção das gelatinas é rica em proteínas e sais minerais, o que a torna um alimento bastante nutritivo. $\mathrm{Na}$ Tabela 3 é apresentada a comparação da composição química entre a gelatina experimental e uma gelatina comercial consolidada no mercado. Pode-se verificar que as quantidades de proteínas e de sódio da gelatina de tarsos de frango é quase quatro vezes maior que as da comercial, isso demonstra uma qualidade extremamente superior da mesma, indicando consequentemente outra vantagem competitiva do produto. 
Tabela 3 - Composição química das gelatinas de tarsos de frango e comercial.

\begin{tabular}{lll}
\hline Constituintes & Valores médios $(\mathbf{g} / \mathbf{1 0 g})$ & \\
\cline { 2 - 3 } & Gelatina de Tarsos de Frango & Gelatina Comercial \\
\hline Umidade & 6,4 & 8,5 \\
& Base seca & $1,6^{* *}$ \\
Proteínas $(\mathbf{g})$ & $6,30^{*}$ & $66 \mathrm{mg}^{* *}$ \\
Sódio $(\mathbf{g})$ & $247 \mathrm{mg}$ &
\end{tabular}

Fonte: *Alves \& Prudêncio-Ferreira (2002) e **Dr. Otker Brasil (2010)

Dessa forma, o consumo diário de uma gelatina obtida a partir de pés de frango equivaleria ao consumo de quatro gelatinas comerciais, mantendo as mesmas propriedades nutricionais e medicinais.

Algumas considerações sobre as vantagens competitivas da gelatina obtida de tarsos de frango devem ser destacadas: o preço de custo para se obter a matéria- prima é irrisório, já que 1 ton custa apenas $R \$ 1,00$ (MFRURAL, 2010). A matéria-prima recebe um destino mais nobre do que os atuais; aumentaria o lucro das indústrias produtoras de carne de frango e com isso melhoraria a qualidade de vida das comunidades circunvizinhas (ALMEIDA et al, 2010). Como cada 1 ton de tarsos de frango gera $355,4 \mathrm{~kg}$ de gelatina (seca) e os pacotes de gelatinas atuais são comercializados com $45 \mathrm{~g}$ (DR. OETKER BRASIL, 2010), pode-se dizer que dessa 1 ton de matéria-prima produzirá 7.898 pacotes de gelatina, com o mesmo $\mathrm{R} \$$ 1,00 gasto em sua aquisição.

\section{CONCLUSÕES}

Estendendo a cadeia produtiva de frango de corte para incluir questões como o aproveitamento de subprodutos acrescenta um nível adicional de complexidade existente no desenho da cadeia, além de um novo potencial estratégico. Entre os elos dessa cadeia, no frigorífico, responsável pelo processamento da carne de frango, onde a competitividade industrial está relacionada à eficiência, à produtividade, à maturidade tecnológica e à sustentabilidade, surge uma nova perspectiva para o destino dos pés de frango como a indústria de gelatina, cada vez mais crescente no Brasil. Nesta por sua vez, foi proposta com o presente estudo a inovação em tipo de matéria-prima citando os pés de frango e novo processo de extração do colágeno determinando adaptabilidade e flexibilidade no processamento.

A proposta de reaproveitamento de um resíduo da avicultura apresentou a obtenção de um alimento de alta qualidade, sendo que a matéria- prima possui preço irrisório e tem aspecto sanitário mais aceitável ao ser humano que a raspa do couro de suínos e bovinos. Esses fatores associados às qualidades químicas e sensoriais viabilizam a substituição da matéria- prima utilizada atualmente pela apresentada nesse trabalho, visando uma atividade de maior sustentabilidade.

O presente estudo dentro da perspectiva de cadeia produtiva do frango de corte teve foco no quinto elo "frigorífico", porém para próximos estudos acredita-se serem relevantes informações mais aprofundadas sobre a indústria de gelatina especificamente, já que se trata de uma área ainda pobre em pesquisas. 


\section{REFERÊNCIAS}

ABEF. Associação Brasileira dos Produtores e Exportadores de Frango. Relatório Anual 2009/2010. Disponível em:<www.abef.com.br> Acesso em: 1 abr. 2011.

ABEF. Associação Brasileira dos Exportadores de Frangos. Exportação Brasileira de Carne de Frango. 2009. Disponível em: <http://www.abef.com.br> Acesso em: out.2009.

ALMEIDA, P. F.; ARAÚJO, M. G. O.; LOPES, F. L. G.; SANTANA, J. C. C.; SOUZA, R. R. Produção de geléias de pés de frango: uma alternativa para agregar valor à avicultura. In: II Simpósio de Ciência e Tecnologia de Alimentos e I Congresso Do Instituto Nacional de Frutos Tropicais. Anais... Aracaju - SE: EDUFS, Abril de 2010.

ALMEIDA, P. F.; SANTANA, J. C. C. Avaliação da Qualidade de uma Gelatina obtida a Partir de Tarsos de Frango. In: XXX Encontro Nacional de Engenharia de Produção, 2010, São Carlos. Anais... São Carlos, SP: EDUFSCAR, v.1, p.1-9, 2010.

ALVES, S. G. T.; PRUDÊNCIO-FERREIRA, S. H. P. Propriedades funcionais de material colagenoso de pés de frango. ALAN, Venezuela, v. 52, n. 3, p. 289-293, 2002.

ANERSEN, J. A.; GILDBERG, A. Extraction and characterisation of gelatin from Atlantic salmon (Salmo salar) skin. Bioresource Technology, n. 98, p. 53-57, 2007.

ARAÚJO, G. C. de; BUENO, M. P.; BUENO, V. P.; SPROESSER, R. L.; SOUZA, I. F. de. Cadeia produtiva da avicultura de corte: avaliação da apropriação de valor bruto nas transações econômicas dos agentes envolvidos. Gestão \& Regionalidade, v. 24, n. $72,2008$.

BADII, F.; HOWELL, N.K. Fish gelatin: Structure, gelling properties and interaction with egg albumen proteins. Food Hydrocolloids, 20, p.630-640, 2006.

BENITES, A. T.; VALÉRIO, L. M. Competitividade - Uma abordagem do ponto de vista teó rico. In: JORNADA CIENTÍFICA DO CENTRO OESTE ECONOMIA E ADMINISTRAÇÃO, 2004, Campo Grande. Anais... Campo Grande, MS, 2004.

BUENO, M. P.; BUENO, V. P.; ARAÚJO, G. C. de.; SOUSA, A. A. de.; SPROESSER, R. L. Gestão da Qualidade nos Frigoríficos de Abate de Frangos Face as Exigências do Mercado Consumidor. In: XIII SIMPOSIO DE ENGENHARIA DE PRODUÇÃO, 2006, Bauru. Anais... Bauru, SP, 2006.

CARDELLO, A. V.; SCHUTZ, H. G. Food appropriateness measures as an adjunct to consumer food preferences/acceptability. Food Quality and Preference, v. 7, n. 3-4, p. 239-249, 1996. 
CASTRO, A. M. G. de. Análise prospectiva de cadeias produtivas agropecuária. Brasília: Embrapa/DPD, 1998. cap. 2. In: Cadeias Produtivas e Sistemas Naturais. Brasília: Embrapa - SPI, 1998.

CHO S. M.; GU Y. S.; KIM S. B. Extracting optimization and physical properties of yellowfin tuna (Thunnus albacares) skin gelatin compared to mammalian gelatins. Food Hydrocolloids, v. 19, p. 221-229, 2005.

DIAS, S. Capacitação e desenvolvimento de fornecedores. In: Pesquisa: $O$ cenário da gestão de suprimentos no Rio Grande do Sul. Núcleo Estratégico de Suprimentos - SEBRAE, RS, 2009.

DR. OETKER BRASIL. Produtos: Gelatinas. Disponível em: <http://www.oetker.com.br> acesso em: 20 abr. 2010.

EVANGELISTA, J. Tecnologia de Alimentos. 2aed. São Paulo: Atheneu, 1989.

FAKHOURI, F. M.; FONTES, L. C.; GONÇALVES, C. M. STEEL, C. J.; COLLARESQUEIROZ, F. P. Filmes e coberturas comestíveis compostas à base de amidos nativos e gelatina na conservação e aceitação sensorial de uvas Crimson. Ciênc. Tecnol. Aliment. Campinas, v. 27, n. 2: p. 369-375, 2007.

FERREIRA, V. L. P. Análise sensorial - Testes discriminativos e afetivos. Campinas: Sociedade Brasileira de Ciência e Tecnologia de Alimentos, p. 73-77, 2000.

FREITAS, I. F. de. Organização da cadeia produtiva de carne de frango no Brasil. 2008. Trabalho de conclusão de curso (Especialização) - Pró-Reitoria de pesquisa e pós-graduação, Universidade Castelo Branco, Rio de Janeiro, RJ.

GELITA. A produção de gelatina. Manual. [online] Disponível em: $<$ http://www.gelita.com/DGF-deutsch/broschuere/pdf/a_producao_de_gelatina.pdf $>$. Acesso em: 18 Abril, 2010.

GIMÉNEZ, B.; TURNAY, J.; LIZARBE, M. A.; MONTERO, M. P.; GÓMEZ-GUILLÉN, M. C.Use of lactic acid for extraction of fish skin gelatin. Food Hydrocolloids, v. 19, p. 941-950, 2005.

GUDMUNDSSON, M. Rheological properties of fish gelatins. Journal of Food Science, v. 67, p. 2172-2176, 2002.

HAUG, I. J.; DRAGET, K. I.; SMIDSROD, O. Physical and rheological properties of fish gelatin compared to mammalian gelatin. Food Hydrocolloids, v. 8, p. 203-213, 2004.

JANK, M. S. Competitividade no agribusiness brasileiro: discussão teórica e evidências no sistema carnes. 1996. Tese (Doutorado em Administração) Departamento de Administração, Universidade de São Paulo, São Paulo, SP, 1996. 
JIAN, C.; LV, Y.; CHANG, G.; TANG, K. lutaraldehyde modification of collagen hydrolysate obtained from chrome shavings. Journal of the American Leather Chemists Association, v. 100, n. 7, p. 265-272, 2005.

LINTON, J. D.; KLASSEN, R. JAYARAMAN, V. Sustainable supply chains: An introduction. Journal of Operations Management, v. 25, p. 1075-1082, 2007.

LOPES, R. L. T. Utilização de tarsos de aves para elaboração de gelatina comestível. 1976. Dissertação (Mestrado em Tecnologia de Alimentos) - Programa de Pós-Graduação em Tecnologia de Alimentos, Universidade Estadual de Campinas, UNICAMP, Campinas, SP, 1976.

MARTINS, F. M. M.; TALAMINI, D. J. D.; NOVAES, M. Avicultura: situação e perspectivas brasileira e Mundial. EMBRAPA, 2006.

MELO, D. de C.; ALCÂNTARA, R. L. C. Desafios identificados na Gestão da Demanda em cadeias de suprimentos agroalimentares. In: XVI Simpósio de Engenharia de Produção, Botucatu, 2009. Anais... Botucatu, SP, 2009.

MFRURAL - Classificados. Produtos rurais: preço dos pés de frango. Atualizado em 28/01/2010. Disponível em <http://comprarvender.mfrural.com.br/detalhe. aspxcdp=44686\&nmoca=procurocompro-compro-pes-de-frango> Acesso em: 22 fev. 2010.

PADILHA, A. C. M.; LEAVY, S.; SAMPAIO, A.; JERÔNIMO, F. B. Gestão ambiental de resíduos da produção na Perdigão Agroindustrial S/A - Unidade Industrial de Serafina Corrêa - RS. In: XLIII Congresso da Sober, Ribeirão Preto, 2005. Anais... Ribeirão Preto, SP, 2005.

PADILHA, A. C. M.; SILVA, T. N.; SAMPAIO, A. Desafios de adequação à questão ambiental no abate de frangos: o caso da Perdigão Agroindustrial - Unidade Industrial de Serafina Corrêa - RS. Teoria e Evidência Econômica, v. 14, ed. especial, p. 109-125, 2006.

PAIVA, C. J.; BUENO, M. P.; SAUER, L.; SPROESSER, R. L. Evolução da gestão da qualidade segundo o programa nacional de sanidade avícola. Revista Avicultura Industrial, n. 10, ed. 1139, 2005.

PALHARES, J. C. P. Novo desafio para avicultura: a inserção das questões ambientais nos modelos produtivos. In: Conferência Apinco de Ciência e Tecnologia Avícolas. 2005, Santos. Anais... Campinas: Facta, 2005.

PARDI, M. C. Ciência e higiene da carne. Tecnologia da sua transformação. $1^{\mathrm{a} e d .}$ v. 1. Goiânia: EDUFF, 1995.

PEREIRA, C. M. M. de A.; MELO, M. R.; SANTOS, M. H. O Agronegócio do frango de corte: um estudo de caso sob a ótica da economia dos custos de transação. Informações Econômicas, São Paulo, v. 37, n. 1, Janeiro, 2007. 
QUEVEDO, A. Gelatina de suíno. Avicultura Industrial, Redação SI - 185, 2005. Disponível em:< http://luizmeira.com/suinos.htm\#gelatina> Acesso em: 20 abr. 2010. ROUSSELOT. Rousselot gelatinas. Disponível em: <www.rousselot.com> Acesso em: 13 Julho, 2010.

ROQUE, V. F. Aproveitamento de resíduos de carne de frango: uma análise exploratória. 1996. Dissertação (Mestrado em Engenharia de Produção) Universidade Federal de Santa Catarina, Florianópolis, 1996.

SARCINELLI, M. F.; VENTURINI, K. S.; SILVA, L. C. DA. Processamento da carne de frango. Universidade Federal do Espírito Santo - UFES, Boletim Técnico - PIEUFES. 2007.

SEBRAE. Pesquisa: O cenário da gestão de suprimentos no Rio Grande do Sul. Núcleo Estratégico de Suprimentos. SEBRAE, RS, 2009.

SERRA, J. R.; OLIVEIRA, O. J.de. Um estudo inicial sobre a oportunidade de aproveitamento de resíduos de raspas de couro na produção de pisos. In: XIII Simpósio de Engenharia de Produção, Bauru, 2006. Anais... Bauru, SP, 2006.

SIMON, A. T.; SATOLO, E. G. Uma análise do complexo sucroalcooleiro sob a ótica da Gestão da Cadeia de Suprimentos (SCM). XVI SIMPÓSIO DE ENGENHARIA DE PRODUÇÃO, Botucatu, 2009. Anais... Botucatu, SP, 2009.

STONE, H.; SIDEL, J. L. Sensory evaluation practices. $2^{\mathrm{a} e d}$. San Diego: Academis Press, 1993, p. 338.

TEIXEIRA, E.; MEINERT, E. M.; BARBETTA, P. A. Análise Sensorial de Alimentos. Série Didática. Florianópolis: Editora UFSC, 1987.

UBA - União Brasileira de Avicultura. Relatório anual 2009. Brasília 2009. Disponível em: <http://www.uba.org.br>. Acesso em: 12 jul. 2010.

UBA - União Brasileira de Avicultura. Relatório anual 2006. Disponível em: <http://www.uba.org.br>. Acesso em: 12 Julho, 2010.

VIEIRA JÚNIOR, P.; LIMA, F. DE; BELIK, W. A. Agentes e instituições da cadeia produtiva do frango de corte. Asociación Latinoamericana de Sociología Rural ALASRU. 2006. Disponível em:< http://www.alasru.org> Acesso em: 21 jul.2010.

YAN, H.; WANG, Y.; JIANG, M.; OH, J. H.; HERRING, J.; ZHOU, P. 2-Step optimization of the extraction and subsequent physical properties of channel catfish (Ictalurus punctatus) skin gelatin. Journal of Food Science, v. 72, n. 4, C188-C195, 2007. 